\title{
Stability of Genetic Evaluations for Active Artificial Insemination Bulls
}

\author{
R. L. Powell, A. H. Sanders, and H. D. Norman \\ Animal Improvement Programs Laboratory, Agricultural Research Service, \\ USDA, Beltsville, MD 20705-2350
}

\begin{abstract}
Genetic evaluations for milk, fat, and protein from 1995 through August 2003 for 17,987 Holstein bulls in active artificial insemination (AI) service were examined for changes to the November 2003 evaluation. Evaluations for active AI bulls at each of 31 evaluation dates showed mean declines to November 2003. No evidence was seen of a worsening situation over time. Bulls' early evaluations with active AI status showed much larger declines, but this overevaluation diminished and essentially disappeared after $3 \mathrm{yr}$. The bulls with first active AI evaluations since 1995 were the primary focus of the study. The influx of second-crop daughters did not appear to cause a decline in evaluations for these bulls, attesting to the successful modification to the genetic evaluation system by expanding the genetic variance of short records. Mean declines and the variation of those differences were generally similar by bull sampling organization. A change from active to inactive AI status was generally concurrent with a decline in predicted transmitting ability (PTA). Bulls coded as having standard AI sampling declined less than bulls coded as having other sampling, but the differences were much less than in previous reports. Larger increases in reliability were generally associated with greater declines in PTA, and the magnitude of these changes decreased over time (increasing evaluation number). Change in reliability underpredicted the variance of change in PTA, indicating that other important factors contribute or that the assumptions for the calculation of the expected change in PTA are not met. Declines in estimated merit over time are not sufficient to alter present genetic selection programs, but reasons for the declines continue to elude explanation. (Key words: bull evaluation, evaluation stability, artificial insemination, genetics)
\end{abstract}

Abbreviation key: NAAB = National Association of Animal Breeders, REL $=$ reliability .

Received December 3, 2003.

Accepted April 2, 2004.

Corresponding author: R. Powell: e-mail: rpowell@aipl.arsusda.

\section{INTRODUCTION}

One constant subject in discussions of dairy bull evaluation is the stability of genetic estimates over time. Sire selection is an area of great importance to producers, breeders, and the AI industry. It seems that this attention creates a tendency to focus primarily on evaluations that change substantially (especially those that decline) and raises questions about the evaluation system. The validity of this concern deserves investigation. Genetic improvement depends on the accuracy of evaluations, and decisions based on faulty information reduce progress.

Meinert and Pearson (1992) reported that yield evaluations for Holstein bulls with second-crop daughters increased for about 2 yr following the initial progeny test evaluation and then declined. The addition of second-crop daughters resulted in a further decline in evaluations of non-AI-sampled bulls, whereas the evaluations of AI-sampled bulls recovered fully. Conclusions were that early second-crop daughters for AI-sampled bulls created an unjustified drop in evaluations and that the first-crop daughters of many non-AI-sampled bulls had received preferential management inflating those genetic evaluations.

A study of over 14,000 Holstein AI bulls born after 1979 showed only a small decline in mean evaluation between the January 1995 and May 2000 evaluations (Powell and Norman, 2001). However, the individual bull variation was larger than expected, considering the increases in reliability (REL); larger increases in mean REL were associated with greater declines in evaluations. Bulls with PTA in the top decile in 1995 showed more notable decline, and the PTA changes were more variable. Large declines were not evident for bulls progeny-tested by major AI organizations. Greater declines in PTA for bulls not progeny-tested through AI organizations were also noted in prior studies by Cassell et al. (1992) and Powell et al. (1994).

With more genetic evaluations per year, changes occur more often, but changes between consecutive runs are smaller (Powell and Norman, 1999). Whether this suggests more stability to the user (smaller changes) or less stability (changes more often) is a topic of conjec- 
ture. The standard deviation of PTA changes between consecutive quarterly evaluations was only about twothirds that of consecutive semi-annual evaluations.

Active AI bulls are, by definition, those bulls actively marketed by the AI organizations, and they represent the vast majority of semen available for purchase and use. The objective of this study was to examine the stability of genetic evaluations for yield of Holstein bulls with active AI status during the period from 1995 through 2003. Bull status is reported to the Animal Improvement Programs Laboratory of USDA by the National Association of Animal Breeders (NAAB). Later evaluations of these bulls (with inactive AI status) were also included. Stability is a general term covering both bias, which will be measured as the mean difference from the November 2003 evaluation for definable groups of bulls, and variability (the amount of variation about the mean change), which will be measured as the standard deviation of the mean differences.

\section{MATERIALS AND METHODS}

\section{Data}

Data were US domestic genetic evaluations from the period between January 1995 and November 2003 for Holstein bulls with active AI status during that time. All evaluations were converted to the current US base. Two sets of data were analyzed: 1 ) all active AI evaluations from that period, including evaluations for bulls active prior to 1995, and 2) all active and subsequent evaluations through August 2003 for bulls whose first active AI evaluation was in 1995 or later. The first data set provided an opportunity to examine the quality of information of most importance for breeding decisions at each evaluation date. Most analysis of accuracy and bias over time involved the second data set. Sampling code (NAAB, 2003) $(\mathrm{S}=$ standard sampling; $\mathrm{O}=$ other) was required, as bulls without a sampling code are foreign bulls whose evaluation characteristics may not be comparable with those sampled domestically. Evaluations in both data sets were matched with the corresponding November 2003 evaluation.

Prior to 1997, evaluations were only in January and July; later, they were in February, May, April, and November. January evaluations were considered to be in February, and July evaluations were considered to be in August, to harmonize the assignment of evaluation numbers. For the second data set, these evaluation numbers were assigned to the first active (1), and all subsequent evaluations for each bull using 3-mo increments. Thus, consecutive evaluations in 1995 and 1996 were assigned only odd evaluation numbers, and although only 31 USDA evaluation dates were included, 35 was the highest evaluation number assigned (to Au- gust 2003 evaluation for bulls first active in January 1995).

\section{Methods}

Means and standard deviations of differences between earlier yield (milk, fat, protein) PTA and the corresponding November 2003 PTA were computed. Analysis of the first data set, including only evaluations with active AI designation, allowed examination of changes in bias or variability of the evaluations for active AI bulls over time. The same mean differences and standard deviations were computed for the second data set, including first active AI evaluations since 1995 and the subsequent evaluations (regardless of AI status) for those bulls through August 2003. Statistics for these data were also computed using only the first active AI evaluation for each bull. Mean differences and standard deviations were also computed by evaluation number within bull. As each increase of one evaluation number represented $3 \mathrm{mo}$, this part of the study analyzed bias and variation over the "life" of a bull's evaluation, whether or not the bull remained active or alive.

Changes in evaluations were also examined by sampling organization (company conducting the progeny test) and by sampling status code ( $\mathrm{S}=$ standard sampling; $\mathrm{O}=$ other). Code ' $\mathrm{S}$ ' bull evaluations should be more accurate and stable because the requirement for the code (distribution of semen to a minimum of 40 herds whose records qualify for USDA genetic evaluation and recording of the bull with NAAB by $3 \mathrm{yr}$ of age) generally leads to a wider sampling, higher REL, and less opportunity for bias and future changes.

The change in PTA from the last evaluation with active status to the first with inactive status was determined for each bull. This difference was used to examine whether changes in yield PTA were associated with assignment to inactive status. Subsequent change was evaluated by comparing these evaluations to the corresponding November 2003 evaluations.

The relationship between changes in PTA and the standard deviations of change with increasing REL was examined. Expected standard deviations (SD) of change were computed as

$$
\begin{gathered}
\mathrm{E}(\mathrm{SD} \text { of change })=\sqrt{(\text { change in REL })} \\
\times(\text { sire genetic SD })
\end{gathered}
$$

(Powell and Norman, 1981), where sire genetic SD was that provided by the Interbull Center (International Bull Evaluation Service, 2003). 


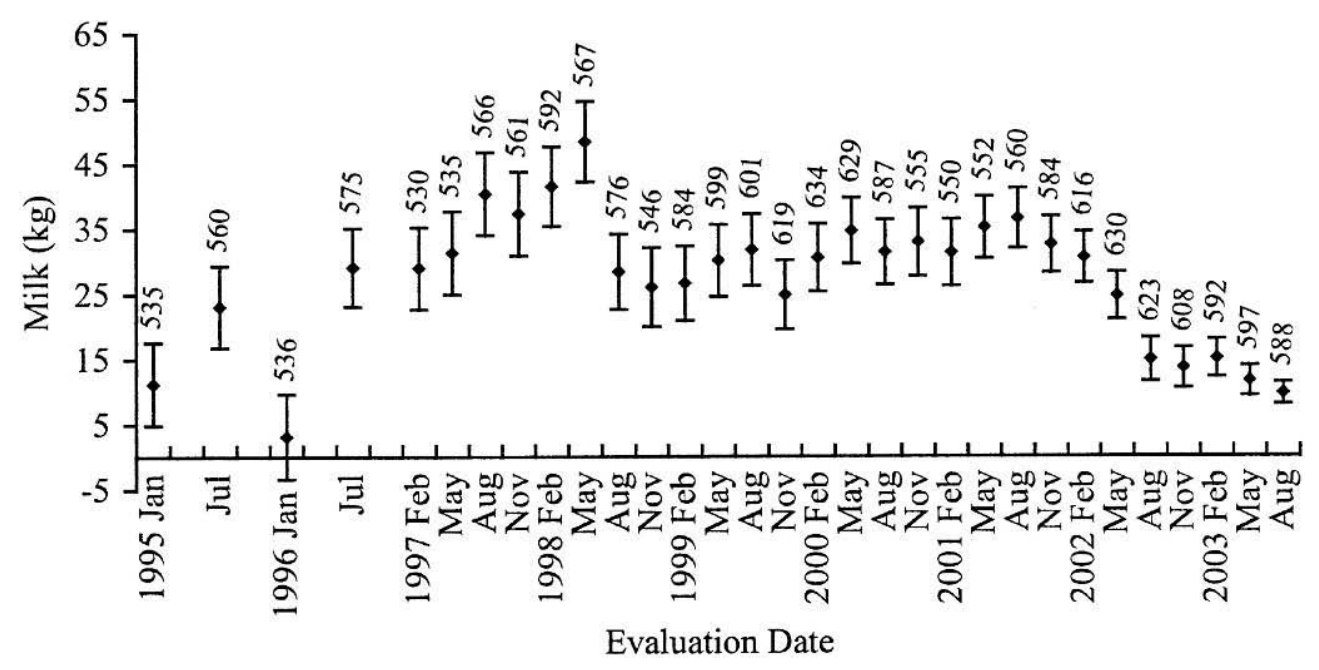

Figure 1. Mean decline in PTA milk to November 2003 evaluations for the active AI evaluations of Holstein bulls in each USDA evaluation. Number of active AI evaluations is above the standard error bar.

\section{RESULTS AND DISCUSSION}

For each of the 31 USDA evaluations in 1995 through August 2003, differences between evaluations of bulls with active AI status and their corresponding evaluation in November 2003 were examined. Mean differences and standard errors of differences for milk PTA are presented in Figure 1. Results for fat and protein were similar, supporting the same conclusions. Numbers of active AI bulls per evaluation date ranged from 530 to 634 . For all evaluation dates, mean differences showed a decline in PTA, and although the differences were relatively small overall (3 to $48 \mathrm{~kg}$ for PTA milk), they were statistically significant for most evaluation dates. Declines were less for the most recent evaluations, almost certainly because of a shorter time for adding data (longer records in progress, later lactation records, and new daughters) that could lower evaluations further. The standard errors for differences were fairly consistent (mean $=4.9 \mathrm{~kg}$ ) but decreased rapidly for the most recent evaluations (Figure 1), which was also likely related to the reduced time for change.

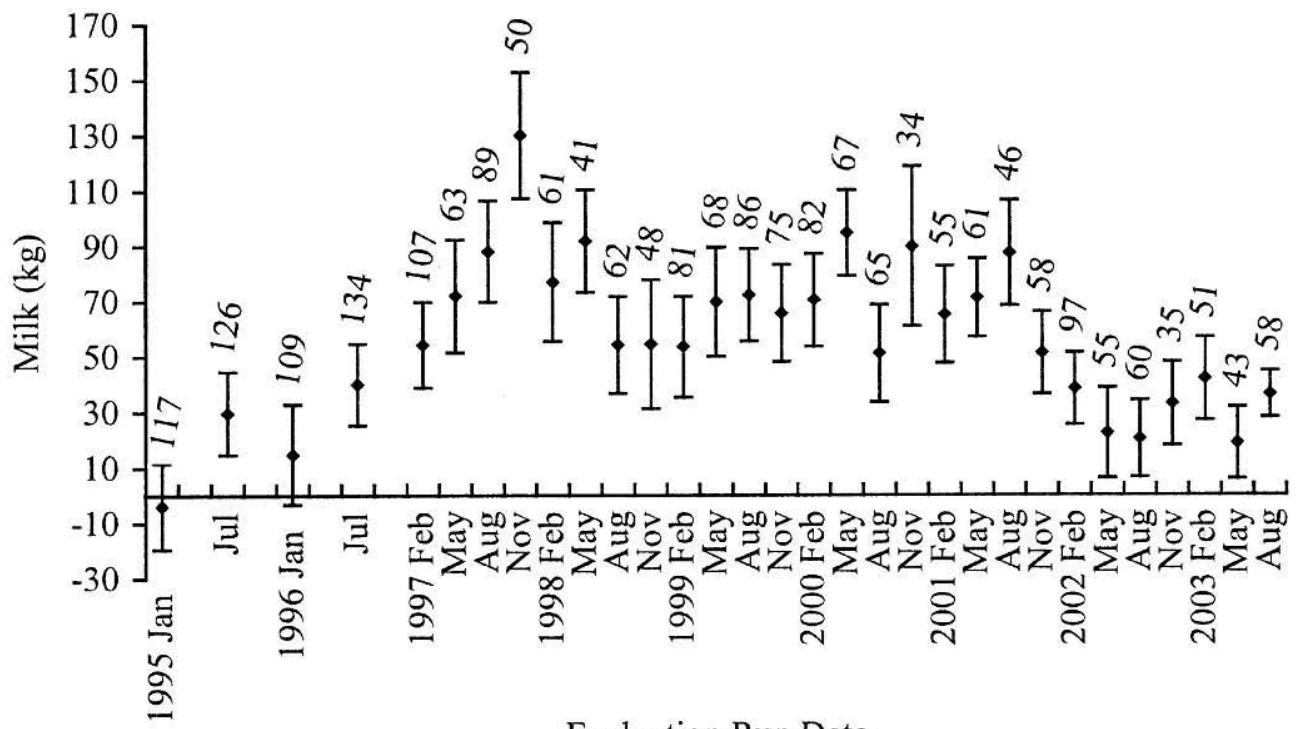

Evaluation Run Date

Figure 2. Mean decline in PTA milk to November 2003 evaluations for the first active AI evaluations of Holstein bulls in each USDA evaluation. Number of first active AI evaluations is above the standard error bar. 
Table 1. Mean PTA and reliability (REL) changes from evaluations 1 through 16 to November 2003 for bulls first entering active AI status prior to 1998, the minimum interval for change thus being over 2 yr. First active AI evaluation is number 1, and evaluation interval is $3 \mathrm{mo}^{1}$

\begin{tabular}{|c|c|c|c|c|c|c|}
\hline \multirow[b]{2}{*}{$\begin{array}{l}\text { Evaluation } \\
\text { number }\end{array}$} & \multirow[b]{2}{*}{$\begin{array}{l}\text { Evaluations } \\
\text { (no.) }\end{array}$} & \multicolumn{3}{|c|}{ Mean PTA change (kg) } & \multicolumn{2}{|c|}{ Milk REL (\%) } \\
\hline & & Milk & Fat & Protein & Mean & $\begin{array}{l}\text { Mean } \\
\text { change }\end{array}$ \\
\hline 1 & 795 & -44 & -2.1 & -1.6 & 74 & 19 \\
\hline 2 & 309 & -66 & -2.9 & -2.3 & 78 & 14 \\
\hline 3 & 795 & -34 & -1.8 & -1.3 & 79 & 14 \\
\hline 4 & 443 & -37 & -2.1 & -1.4 & 81 & 11 \\
\hline 5 & 795 & -26 & -1.6 & -0.9 & 82 & 11 \\
\hline 6 & 552 & -30 & -1.7 & -1.1 & 83 & 10 \\
\hline 7 & 795 & -24 & -1.4 & -0.8 & 83 & 10 \\
\hline 8 & 678 & -22 & -1.3 & -0.8 & 84 & 9 \\
\hline 9 & 795 & -15 & -1.2 & -0.6 & 85 & 9 \\
\hline 10 & 795 & -10 & -1.0 & -0.4 & 85 & 8 \\
\hline 11 & 795 & -6 & -0.8 & -0.3 & 86 & 8 \\
\hline 12 & 795 & 0 & -0.6 & -0.1 & 86 & 7 \\
\hline 13 & 795 & 6 & -0.4 & 0.1 & 87 & 7 \\
\hline 14 & 795 & 9 & -0.1 & 0.1 & 88 & 5 \\
\hline 15 & 795 & 10 & 0.1 & 0.2 & 90 & 4 \\
\hline 16 & 795 & 7 & 0 & 0.2 & 91 & 2 \\
\hline
\end{tabular}

${ }^{1}$ Numbers are less for some even-numbered evaluations because bulls had only odd-numbered evaluations (every 6 mo) prior to February 1997.

Figure 2 shows mean changes from 2184 first active AI evaluations to the corresponding November 2003 evaluations. These also consistently indicate declines in evaluations. Overall, mean declines from first active $\mathrm{AI}$ evaluation to November 2003 were 53, 2.4, and 1.8 $\mathrm{kg}$ for milk, fat, and protein, respectively. These are nearly twice the overall mean declines observed for all active AI evaluations (27, 1.6, and $0.9 \mathrm{~kg}$ ). Declines might be larger from first active AI evaluations because of inflated parent averages that have diminished impact as numbers of daughters increase. For the 353 bulls that became active since 1995 and had reached
99\% yield REL in November 2003, mean declines from first active AI evaluations were only $32,2.1$, and 1.5 $\mathrm{kg}$ for milk, fat, and protein, respectively. This is not surprising because bulls that are underevaluated would increase in PTA, remain in service, and attain 99\% REL, and corresponding bulls that are overevaluated would tend to decline and be eliminated before reaching 99\% REL. Mean REL of the first active AI evaluation was only slightly higher for these bulls. First active AI evaluations might also be high if early daughter yield deviations (VanRaden and Wiggans, 1991) were inflated or the heritability used in evaluations was not optimum. The heritability used in calculating US evaluations was increased from 0.25 to 0.30 in 1997 based on research described by Van Tassell et al. (1999).

Examining the differences between each evaluation since the first active AI evaluation and the corresponding November 2003 evaluation showed that a large part of the overall decline in evaluation occurred in the earlier active evaluations. Mean changes in evaluations relative to the November 2003 evaluation, for evaluations 1 through 16 of bulls entering active AI status prior to 1998, are presented in Table 1 . The 1998 cutoff provided a minimum interval of $2 \mathrm{yr}$ from evaluation number 16 to November 2003. Decrease in PTA becomes less as evaluation number increases, becoming essentially zero by evaluation number 12 . Historically, the influx of in-progress first lactation records on second-crop daughters caused a drop in PTA at about evaluation 13 (3 yr after first active AI evaluation) (Meinert and Pearson, 1992). The work of VanRaden et al. (1991), which was intended to alleviate this problem by expanding the genetic variance of short records to match that of complete records more closely, seems to have been successful. Mean differences between the 13th evaluation and the November 2003 evaluation for all

Table 2. Numbers and relative current ages of bulls, means and standard deviations of PTA changes, and mean reliability (REL) and changes from initial active AI evaluation to November 2003 evaluation by sampling organization for Holstein bulls with first active AI evaluations during 1995 through August 2003.

\begin{tabular}{|c|c|c|c|c|c|c|c|c|c|c|}
\hline \multirow[b]{2}{*}{$\begin{array}{l}\text { Sampling } \\
\text { organization }\end{array}$} & \multirow[b]{2}{*}{$\begin{array}{l}\text { Bulls } \\
\text { (no.) }\end{array}$} & \multirow[b]{2}{*}{$\begin{array}{l}\text { Mean evaluation } \\
\text { interval }^{1}(\mathrm{mo})\end{array}$} & \multicolumn{2}{|c|}{ Milk REL (\%) } & \multicolumn{2}{|c|}{ Milk PTA (kg) } & \multicolumn{2}{|c|}{ Fat PTA (kg) } & \multicolumn{2}{|c|}{ Protein PTA (kg } \\
\hline & & & Mean $^{2}$ & $\begin{array}{l}\text { Mean } \\
\text { change }\end{array}$ & $\begin{array}{l}\text { Mean } \\
\text { change }\end{array}$ & $\mathrm{SD}$ & $\begin{array}{l}\text { Mean } \\
\text { change }\end{array}$ & $\mathrm{SD}$ & $\begin{array}{l}\text { Mean } \\
\text { change }\end{array}$ & $\mathrm{SD}$ \\
\hline B & $>200$ & 57 & 82 & 13 & -38 & 144 & -1.9 & 5.2 & -1.5 & 3.9 \\
\hline $\mathrm{C}$ & $>200$ & 51 & 80 & 12 & -83 & 148 & -3.1 & 5.6 & -2.6 & 4.3 \\
\hline $\mathrm{D}$ & $>150$ & 58 & 76 & 16 & -57 & 157 & -2.3 & 5.5 & -1.8 & 4.3 \\
\hline $\mathrm{E}$ & $>150$ & 55 & 81 & 14 & -49 & 134 & -2.0 & 5.3 & -1.5 & 3.9 \\
\hline $\mathrm{H}$ & $>100$ & 44 & 65 & 15 & -45 & 160 & -2.0 & 5.5 & -1.4 & 4.6 \\
\hline
\end{tabular}

${ }^{1}$ Interval from first active AI evaluation until November 2003.

${ }^{2}$ For first active AI evaluations.

${ }^{3}$ Grouping of 110 smaller organizations. 
Table 3. Mean changes in yield evaluations and reliabilities (REL) between last active AI evaluation, first inactive evaluation, and November 2003 evaluation for Holstein bulls with first active AI evaluations during 1995 through May 2003 and inactive status by August 2003 ( $\mathrm{n}=1356)$.

\begin{tabular}{lcccc}
\hline Change & Milk $(\mathrm{kg})^{1}$ & Fat $(\mathrm{kg})^{1}$ & ${\text { Protein }(\mathrm{kg})^{1}}^{1}$ & REL (\%) \\
\hline $\begin{array}{l}\text { Last active AI evaluation to next } \\
\quad \text { first inactive) evaluation }\end{array}$ & $-20 \pm 57$ & $-0.6 \pm 2.1$ & $-0.6 \pm 1.6$ & 1.7 \\
$\begin{array}{l}\text { First inactive evaluation to } \\
\quad \text { November 2003 evaluation }\end{array}$ & $-12 \pm 110$ & $-0.8 \pm 3.8$ & $-0.4 \pm 3.0$ & 6.6 \\
$\begin{array}{l}\text { Last active AI evaluation to } \\
\text { November 2003 evaluation }\end{array}$ & $-32 \pm 121$ & $-1.4 \pm 4.3$ & $-1.0 \pm 3.3$ & 8.2 \\
\hline
\end{tabular}

${ }^{1}$ Mean changes \pm SD of changes.

1531 bulls entering active AI service from 1995 through August 2003 were $3,-0.5$, and $0 \mathrm{~kg}$ for milk, fat, and protein, respectively, nearly identical to the results in Table $1(6,-0.4,0.1 \mathrm{~kg})$, where the 13 th evaluation was at least $3 \mathrm{yr}$ before November 2003.

The changes from the first active AI evaluation to the November 2003 PTA were generally similar across sampling organizations. Table 2 contains the results for the 7 organizations with the largest numbers of bulls plus the other 110 sampling organizations considered as a group. The number of active AI bulls per organization ranged from 1 to 282 , and a total of 1293 bulls were marketed by the 7 largest organizations. The 2 largest organizations show the greatest differences in mean PTA changes represented in the table, although mean REL are nearly the same. These differences may be of less consequence when considering the variation among all organizations. The distribution over time of bulls marketed could also influence comparison between organizations.

From July 1995 through August 2003, 1356 bulls had their AI status changed from active to inactive. More than one-half of the bulls had $<6$ active evaluations. Table 3 contains data relating to changes in PTA from the last active evaluation to the first inactive evaluation, and each of these is related to the November 2003 evaluation. The last active AI evaluations were higher than the following inactive evaluation by averages of $20,0.6$, and $0.6 \mathrm{~kg}$ for milk, fat, and protein, respectively. A decline is expected because bulls' status is determined after the evaluations are made available; thus, bulls whose evaluations drop are more likely to be given inactive status. The decision to make a bull inactive is also affected by evaluations for other traits and semen availability, and first inactive evaluations were lower for only 63,55 , and $57 \%$ of bulls for milk, fat, and protein, respectively. Only $42 \%$ of bulls dropped in all 3 yield traits. The decision to make a bull inactive was associated with a larger average drop in evaluation than between consecutive active evaluation numbers 1 through 6 (average drops of 5, 0.2, and $0.2 \mathrm{~kg}$ for milk, fat, and protein, respectively). Although evaluations of bulls retaining active status declined more to November 2003 than those assigned inactive status, they continued to be superior. Averaged across runs, the bulls retaining active status were $64,1.5$, and $1.6 \mathrm{~kg}$ superior in November 2003 milk, fat, and protein PTA to the bulls assigned inactive status. At the time of decision, they were superior by $81,2.4$, and $2.2 \mathrm{~kg}$. The decisions generally proved sound as only 29,25 , and $26 \%$ of bulls recovered to the level of their last active evaluation by November 2003 for milk, fat, and protein, respectively.

Table 4. Mean changes in yield evaluations and reliabilities (REL) to November 2003 evaluations for Holstein bulls with active AI evaluations in 1995 through 2003 by sampling status code.

\begin{tabular}{|c|c|c|c|c|c|c|}
\hline Evaluations included & Status $^{1}$ & $\begin{array}{l}\text { Evaluations } \\
\text { (no.) }\end{array}$ & Milk $(\mathrm{kg})^{2}$ & Fat $(\mathrm{kg})^{2}$ & Protein $(\mathrm{kg})^{2}$ & $\begin{array}{l}\text { REL } \\
(\%)\end{array}$ \\
\hline Bulls' first active evaluations from & $\mathrm{S}$ & 1977 & $-52 \pm 149$ & $-2.3 \pm 5.4$ & $-1.8 \pm 4.2$ & 14.3 \\
\hline 1995 through August 2003 & $\mathrm{O}$ & 207 & $-58 \pm 165$ & $-2.2 \pm 6.4$ & $-1.9 \pm 4.6$ & 15.8 \\
\hline first active in 1995 through 2003 & $\mathrm{O}$ & 1707 & $-50 \pm 152$ & $-2.0 \pm 5.9$ & $-1.5 \pm 4.3$ & 9.8 \\
\hline Active and subsequent ${ }^{3}$ evaluations & $\mathrm{S}$ & 35,344 & $-12 \pm 97$ & $-0.8 \pm 3.6$ & $-0.4 \pm 2.7$ & 5.1 \\
\hline for bulls first active in 1995 through 2003 & $\mathrm{O}$ & 4180 & $-20 \pm 114$ & $-0.9 \pm 4.4$ & $-0.6 \pm 3.2$ & 5.4 \\
\hline
\end{tabular}

\footnotetext{
${ }^{1}$ Sampling status $(\mathrm{S}=$ standard, distribution of semen to a minimum of 40 herds whose records qualify for USDA genetic evaluations; $\mathrm{O}=$ other).

${ }^{2}$ Mean changes $\pm \mathrm{SD}$ of changes.

${ }^{3}$ Evaluations through August 2003.
} 
Table 5. Mean changes in yield evaluations by increase in reliability (REL) for active and subsequent evaluations of Holstein bulls with first active AI evaluations during 1995 through 2003.

\begin{tabular}{|c|c|c|c|c|c|c|c|c|}
\hline \multirow{3}{*}{$\begin{array}{l}\text { REL } \\
\text { increase } \\
(\%)\end{array}$} & \multirow{3}{*}{$\begin{array}{l}\text { Evaluations } \\
\text { (no.) }\end{array}$} & \multirow{2}{*}{\multicolumn{4}{|c|}{ Mean changes $^{1}$}} & \multicolumn{3}{|c|}{ Expected SD of changes } \\
\hline & & & & & & \multirow{2}{*}{$\begin{array}{l}\text { Milk } \\
(\mathrm{kg})\end{array}$} & \multirow{2}{*}{$\begin{array}{l}\text { Fat } \\
(\mathrm{kg})\end{array}$} & \multirow{2}{*}{$\begin{array}{l}\text { Protein } \\
(\mathrm{kg})\end{array}$} \\
\hline & & Milk (kg) & Fat $(\mathrm{kg})$ & Protein $(\mathrm{kg})$ & REL (\%) & & & \\
\hline 0 to 5 & 25,496 & $-4 \pm 62$ & $-0.3 \pm 2.3$ & $-0.1 \pm 1.7$ & $1.4 \pm 1.5$ & 38 & 1.4 & 1.0 \\
\hline 6 to 10 & 6553 & $-15 \pm 121$ & $-1.3 \pm 4.3$ & $-0.6 \pm 3.3$ & $7.8 \pm 1.4$ & 90 & 3.3 & 2.4 \\
\hline 11 to 15 & 4359 & $-31 \pm 142$ & $-2.0 \pm 5.1$ & $-1.1 \pm 3.9$ & $12.7 \pm 1.4$ & 114 & 4.1 & 3.0 \\
\hline 16 to 20 & 2012 & $-46 \pm 162$ & $-2.5 \pm 6.0$ & $-1.7 \pm 4.5$ & $17.7 \pm 1.4$ & 134 & 4.9 & 3.5 \\
\hline 21 to 25 & 688 & $-87 \pm 185$ & $-3.7 \pm 6.7$ & $-2.7 \pm 5.1$ & $22.6 \pm 1.4$ & 152 & 5.5 & 4.0 \\
\hline$\geq 26$ & 416 & $-99 \pm 214$ & $-4.1 \pm 7.7$ & $-2.9 \pm 5.9$ & $22.7 \pm 13.0$ & 174 & 6.3 & 4.6 \\
\hline
\end{tabular}

${ }^{1}$ Mean changes $\pm \mathrm{SD}$ of changes.

Bulls with standard sampling code ('S' bulls) nearly always declined less in PTA for yield traits than bulls with sampling code of other ('O' bulls). Table 4 provides a comparison of means and standard deviations of changes from earlier evaluations to the November 2003 evaluations by sampling status code. The first 3 sections of the table describe evaluations for bulls with first active AI evaluations in 1995 or later. The first section includes only first active evaluations, the second section includes all active AI evaluation for those bulls, and the third section includes the active and all subsequent evaluations for those bulls. The fourth section of the table describes all active AI bulls' evaluations from 1995 on, including bulls whose first active AI evaluation was earlier than 1995. The variation of changes in PTA for 'S' bulls was also less than for ' $\mathrm{O}$ ' bulls. However, these differences are not large in comparison with previous reports. Apparently, sampling of ' $O$ ' bulls is more like that of 'S' bulls for the data in this report than in previous studies. Mean reliability increases were less for 'S' bulls, although a higher mean November 2003 REL was attained (91\% vs. $86 \%$ ) because REL of their first active evaluations were higher $(77 \%$ vs. $70 \%)$

Larger decreases in PTA occurred with increasing REL change (Table 5). This is consistent with the finding that PTA declines lessened with increasing evaluation number. Expected standard deviations of changes were computed as functions of REL increase and sire genetic standard deviation and were based on partwhole assumptions, i.e., that all daughters in the earlier evaluations were also included in the later evaluations. Results in Table 5 show that the actual standard deviations were larger than expected. This could result from change in REL not reflecting true increase in amount of information (e.g., if not all earlier daughters were in the later data). Also, differences in rate of maturity of a bull's daughters relative to typical cows and differing age distributions among their daughters over time would cause larger evaluation changes than expected from increases in REL. For example, a substantial difference in the second lactation performance of a bull's daughters relative to their first lactations may result in a considerable change in PTA with little change in REL.

The regressions of changes in PTA from each evaluation to November 2003 on change in REL within bull were highly significant. For each increase of $1 \%$ in REL change, PTA decreased by $2.9,0.14$, and $0.10 \mathrm{~kg}$ more for milk, fat, and protein, respectively. The quadratic effect for REL change was also significant although the $\mathrm{R}^{2}$ value increased very little (0.002). Bulls with larger increases in REL declined more in PTA than apparent from the linear effect alone, which predicted change accurately at low levels of REL change.

\section{CONCLUSIONS}

Mean yield PTA for active AI bulls declined relative to the November 2003 PTA for all 3 yield traits for all 31 evaluation runs examined. The declines are undesirable, but there was no evidence that they were of a magnitude that would result in important selection errors or that there was a worsening situation over time. A surprising finding was that the early evaluations with active AI status were proportionately larger overestimates of November 2003 evaluations, but this overevaluation diminished and essentially disappeared within $3 \mathrm{yr}$. Mean overestimates of 44,2.1, and $1.6 \mathrm{~kg}$ for milk, fat, and protein PTA, respectively, in first active AI evaluations were reduced to almost one-half of that after $1 \mathrm{yr}(26,1.6$, and $0.9 \mathrm{~kg}$, respectively).

The influx of second-crop daughters caused no apparent decline in evaluations. The modification to the genetic evaluation system to expand the genetic variance of short records appears to have been successful, although other factors may also have been at work. Mean decline and the variation of those differences were similar by bull sampling organization.

Bulls' change from active to inactive AI status was generally concurrent with a decline in yield PTA, although other factors might have precipitated some of the decisions to change AI status. Bulls assigned inactive status had lower November 2003 yield evaluations 
than did bulls continuing in active status, validating the use of available yield evaluations in making status change decisions.

Sampling status was also related to changes in PTA over time. The 'S' bulls declined less than 'O' bulls, but the differences were much less than in previous reports. It seems that the sampling programs are less different, and biases for bulls outside the standard sampling are less than in the past. Also, this study included only bulls that entered active AI service, a step that may be taken with greater discrimination than in earlier times.

Bulls tended to decline with increases in REL. Change in REL underpredicted the standard deviations of change, indicating that there are other important factors not included in REL or that the assumptions for the calculation of the expected variation of change are not met.

The general decline in evaluations during the accumulation of first-crop data but not thereafter suggests positively biased parent averages whose impact lessens with more daughter data. However, there may also be a tendency to select bulls for active service that have had an unrepresentative sample of favorable daughter information in the progeny test data leading to the decision. The decline in early active AI evaluations should be considered in decisions to market bulls (assign active status) and also decisions involving mating sires (sires for sons to sample). In practice, this can be (and likely already is) handled by revisiting the decision when a resulting bull calf is born or before semen is released. By the time semen is released from a son sired by a bull that had only one active run at the time, there have been at least 7 more evaluations. Changes in evaluations are lessened with wider sampling and higher REL requirements for active status, but these actions come with costs. Until the reasons for PTA declines across time are understood, continued research is needed.

\section{REFERENCES}

Cassell, B. G., R. E. Pearson, M. L. McGilliard, and T. R. Meinert. 1992. Genetic merit and usage patterns of bulls from different sampling programs. J. Dairy Sci. 75:572-579.

International Bull Evaluation Service. 2003. Interbull routine genetic evaluation for dairy production traits, November 2003. http:// www-interbull.slu.se/eval/framesida-prod.htm. Accessed December $22,2003$.

Meinert, T. R., and R. E. Pearson. 1992. Stability of evaluations of bulls sampled by artificial insemination and other organizations. J. Dairy Sci. 75:564-571.

National Association of Animal Breeders. 2003. NAAB Dairy Sire Summary. August:2003. National Association of Animal Breeders, Columbia, MO.

Powell, R. L., and H. D. Norman. 1981. Changes in predicted difference milk with increased reliability. J. Dairy Sci. 63:1972-1977.

Powell, R. L., and H. D. Norman. 1999. Examination of more frequent genetic evaluations for dairy bulls. J. Dairy Sci. 82:2766-2770.

Powell, R. L., and H. D. Norman. 2001. Stability and bias of yield evaluations for Holstein bulls in artificial insemination service. J. Dairy. Sci. 84(Aug). Online. Available: http://www.adsa.org/ jds/.

Powell, R. L., G. R. Wiggans, and H. D. Norman. 1994. Effect of sampling status and adjustment for heterogeneous variance on bias in bull evaluations. J. Dairy Sci. 77:883-890.

VanRaden, P. M., and G. R. Wiggans. 1991. Derivation, calculation, and use of national animal model information. J. Dairy Sci. 74:2737-2746.

VanRaden, P. M., G. R. Wiggans, and C. A. Ernst. 1991. Expansion of projected lactation yield to stabilize genetic variance. J. Dairy Sci. 74:4344-4349.

Van Tassell, C. P., G. R. Wiggans, and H. D. Norman. 1999. Method $\mathrm{R}$ estimates of heritability for milk, fat, and protein yields of United States dairy cattle. J. Dairy Sci. 82:2231-2237. 